Cite this: CrystEngComm, 2013, 15, 7321

Received 30th May 2013,

DOI: $10.1039 /$ c3ce40960k

www.rsc.org/crystengcomm
Accepted 10th July 2013

\section{Supramolecular 1D ribbons in complexes between a bicyclic-guanidine derivative and di- or monocarboxylic acids $\dagger$}

\begin{abstract}
Vitthal N. Yadav and Carl Henrik Görbitz*
Zwitterionic crystalline complexes between 1,5,7-triazabicyclo[4.4.0]dec-5-ene (TBD), a guanidine derivative, and two dicarboxylic acids (DCAs) (oxalic acid, adipic acid) as well as a special monocarboxylic acid (glycolic acid) have been analyzed by single crystal X-ray diffraction methods. In the solid state the carboxylic acid forms a monoanion by readily transferring an acidic proton to a TBD base, resulting in formation of strong ${ }^{+} \mathrm{N}-\mathrm{H} \cdots \mathrm{O}^{-}$hydrogen-bonded $\mathrm{R}_{2}^{2}(8)$ ring motifs, while $\mathrm{O}-\mathrm{H} \cdots \mathrm{O}$ interactions expand the network into infinite one-dimensional supramolecular chains. Numerous $\mathrm{C}_{(\mathrm{sp} 3)}-\mathrm{H} \cdots \mathrm{O}$ interactions also contribute in crystal packing, including TBD as a weak donor and $\mathrm{O}$ atoms of carboxyl groups or cocrystallized water molecules as acceptors. The hydrogen bonding and crystal packing of all three complexes have been compared with the respective guanidine-carboxylate or related complexes reported previously.
\end{abstract}

\section{Introduction}

The construction of ordered crystalline networks has been the main focus of supramolecular chemistry in recent decades. To achieve this, molecular recognition through intermolecular non-covalent interactions such as $\mathrm{H}$ bonds is the foremost crystal engineering approach. ${ }^{1}$ In this area organic acids and bases are appealing building blocks because of their innate and robust $\mathrm{H}$-bonding complex formation capacity, including $\mathrm{N}-\mathrm{H} \cdots \mathrm{O}, \mathrm{N} \cdots \mathrm{H}-\mathrm{O}$ and $\mathrm{O}-\mathrm{H} \cdots \mathrm{O}$ interactions. ${ }^{2}$ Unsubstituted guanidine has been extensively incorporated in crystal design and synthesis because of its strong basicity, the unique threefold structural symmetry of the guanidinium cation, and the ability to form charge-assisted ${ }^{+} \mathrm{N}-\mathrm{H}^{\cdots} \mathrm{O}^{-}$hydrogen bonds with carboxylate, phosphonate, sulphonate and nitro groups etc. that often results in formation of the symmetrical $\mathrm{R}_{2}^{2}(8)$ H-bonding motif (Fig. 1a) ${ }^{3}$ in diverse $2 \mathrm{D}$ or $3 \mathrm{D}$ networks. ${ }^{4}$

The guanidine derivative TBD (Fig. 1b) is a rigid and versatile building block that has been widely used as a ligand in co-ordination chemistry ${ }^{5}$ and often serves as a base ${ }^{6}$ or a catalyst $^{7}$ in organic synthesis. Use of $\mathbf{T B D}$ in supramolecular chemistry, on the other hand, has been poorly investigated, and only few crystal structures have been reported. ${ }^{3 f, 7,8}$ Recently, we have demonstrated that the TBD cation with only two donor sites is in fact a structurally interesting building block when combined with a partner bipyridine

Department of Chemistry, University of Oslo, Post box 1033, Blindern, Oslo-0315, Norway. E-mail: c.h.gorbitz@kjemi.uio.no; Fax: +4722855441 $\dagger$ CCDC 905593-905595. For crystallographic data in CIF or other electronic format see DOI: $10.1039 / \mathrm{c} 3 \mathrm{ce} 40960 \mathrm{k}$ dicarboxylate. ${ }^{9}$ Subsequently we have illustrated different structural properties of TBD-carboxylates via several $2: 1$ (TBD : DCA) crystalline complexes which form various H-bonded motifs. In these complexes the anti lone pairs of carboxylate $\mathrm{O}$ atoms often interact with co-crystallized water molecules by $\mathrm{H}$ bonding. ${ }^{10}$ These waters of hydration lead into well organized water clusters, 1D tapes or open channels rather than the hexagonal networks or densely packed structures obtained in native guanidine complexes. ${ }^{4,9,11}$

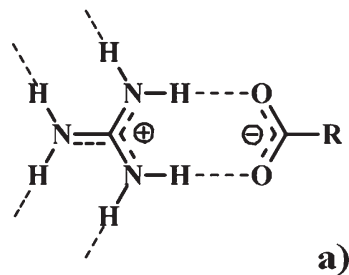

a)<smiles>O=C(O)C(=O)O</smiles>

c)<smiles>CC(C(=O)O)C(=O)O</smiles>

d)<smiles>C1CN=C2NCCCN2C1</smiles>

b)<smiles>O=C(O)CO</smiles>

e)
Fig. 1 a) A hydrogen bonded guanidinium-carboxylate recognition adduct forming $R_{2}^{2}(8)$ motif. b) TBD a base and c) oxalic acid d) adipic acid e) glycolic acid used in complexes. 
In contrast to the earlier $2: 1$ complexes, the present work is focusing on unusual solid-state structures formed by TBD $\left(\mathrm{p} K_{\mathrm{a}}=14.47\right)^{12}$ with oxalic acid (OxT, Fig. $1 \mathrm{c}, \mathrm{p} K_{\mathrm{a} 1}=1.27 ; \mathrm{p} K_{\mathrm{a} 2}=$ 4.27), adipic acid (AdT, Fig. $1 \mathrm{~d}, \mathrm{p} K_{\mathrm{a} 1}=4.41 ; \mathrm{p} K_{\mathrm{a} 2}=5.41$ ) and glycolic acid (GlT, Fig. 1e, $\left.\mathrm{p} K_{\mathrm{a}}=3.83\right) .{ }^{13}$

\section{Experimental}

\section{Materials and general process for crystal preparation}

TBD, oxalic acid, adipic acid and glycolic acid were purchased from Sigma-Aldrich and used as received. X-ray quality single crystals were obtained by dissolving TBD $(2 \mathrm{mmol})$ and the corresponding carboxylic acid $(1 \mathrm{mmol})$ in demineralized water $(2 \mathrm{ml})$. The mixture was stirred for 10 minutes at ambient temperature and kept stationary to evaporate the solvent slowly over $3-4$ weeks. ${ }^{1} \mathrm{H}$-NMR and ${ }^{13} \mathrm{C}$-NMR data for the obtained complexes were recorded at RT using a Bruker DPX300MHz spectrometer. Melting point ( $\mathrm{mp}$ ) measurements were performed using Stuart SMP10 equipment.

\section{TBD:hydrogen oxalate (OxT)}

mp $138-140{ }^{\circ} \mathrm{C}$.

${ }^{1} \mathrm{H}-\mathrm{NMR}, 300 \mathrm{MHz},\left(\mathrm{DMSO}-d_{6}\right) \delta 10.38(\mathrm{~s}, 2 \mathrm{H}), 3.27-3.23(\mathrm{t}$, $8 \mathrm{H}), 3.15-3.11(\mathrm{t}, 8 \mathrm{H}), 1.90-1.82(\mathrm{~m}, 8 \mathrm{H})$.

${ }^{13} \mathrm{C}-\mathrm{NMR}, 300 \mathrm{MHz}$, (DMSO- $\left.d_{6}\right) \delta, 173.09$ (COO), 151.92 $\left(\mathrm{CN}_{3}\right), 46.94\left(\mathrm{CH}_{2}\right), 38.06\left(\mathrm{CH}_{2}\right), 21.39\left(\mathrm{CH}_{2}\right)$.

\section{TBD:hydrogen adipate (AdT)}

$\operatorname{mp} 238-240{ }^{\circ} \mathrm{C}$.

${ }^{1} \mathrm{H}-\mathrm{NMR} 300 \mathrm{MHz},\left(\mathrm{DMSO}-d_{6}+\mathrm{D}_{2} \mathrm{O}\right) \delta, 3.23-3.19(\mathrm{t}, 8 \mathrm{H})$, 3.13-3.09 (t, 8H), 1.94-1.89 (m, 4H), 1.87-1.79 (m, 8H), 1.39$1.34(\mathrm{~m}, 4 \mathrm{H})$.
${ }^{13} \mathrm{C}-\mathrm{NMR} 300 \mathrm{MHz}$, (DMSO- $\left.d_{6}+\mathrm{D}_{2} \mathrm{O}\right) \delta, 180.48$ (COO), $151.69\left(\mathrm{CN}_{3}\right), 46.88\left(\mathrm{CH}_{2}\right), 38.60\left(\mathrm{CH}_{2}\right), 37.88\left(\mathrm{CH}_{2}\right), 26.98$ $\left(\mathrm{CH}_{2}\right), 21.11\left(\mathrm{CH}_{2}\right)$.

\section{TBD:glycolate monohydrate (GIT)}

mp 88-90 ${ }^{\circ} \mathrm{C}$.

${ }^{1} \mathrm{H}-\mathrm{NMR}, 300 \mathrm{MHz}$ (DMSO- $\left.d_{6}\right) \delta, 9.93(\mathrm{~s}, 1 \mathrm{H}), 3.51(\mathrm{~s}, 2 \mathrm{H})$, 3.28-3.24 (t, 4H), 3.17-3.13 (t, 4H), 1.91-1.83 (m, 4H).

${ }^{13} \mathrm{C}-\mathrm{NMR} 300 \mathrm{MHz}$ (DMSO- $\left.d_{6}\right) \delta, 177.29$ (COO), $152.04\left(\mathrm{CN}_{3}\right)$, $62.24\left(\mathrm{CH}_{2}\right), 46.96\left(\mathrm{CH}_{2}\right), 38.05\left(\mathrm{CH}_{2}\right), 21.29\left(\mathrm{CH}_{2}\right)$.

\section{$\mathrm{X}$-ray structure determination}

X-ray intensity data measurements of OxT, AdT and GIT crystalline complexes were carried out on a Bruker SMART APEX II CCD diffractometer with graphite-monochromatized (Mo K $\alpha=0.71073 \AA$ ) radiation at low temperature $(105 \mathrm{~K})$ controlled by an Oxford Cryostream low-temperature device. Data were collected with $\omega$ scan width $0.5^{\circ}$ at three different settings of $\varphi\left(0^{\circ}, 90^{\circ}\right.$ and $\left.180^{\circ}\right)$ with the detector fixed at $2 \theta=$ $-30^{\circ}$. Data integration/reduction and absorption was carried out by SAINT and SADABS, respectively, refinement by SHELXTL. ${ }^{14}$ In these complexes all the $\mathrm{H}-\mathrm{C}$ and the $\mathrm{H}-\mathrm{N}$ hydrogen atoms were constrained to theoretical positions. The carboxylic $(\mathrm{O}-\mathrm{H}) \mathrm{H}$-atoms of OxT and AdT, and an alcoholic $(\mathrm{O}-\mathrm{H})$ and $\mathrm{H}$-atoms of a co-crystallized water molecule in GlT were added from the experimental Fourier difference electron density diffraction map. The GlT water molecule is observed to be disordered over three sites (O1W, O2W and O3W) with refined occupancies $0.900(7), 0.056(7)$ and $0.042(4)$, respectively. The $\mathrm{O}-\mathrm{H}$ bond lengths of the water molecule were subject to SHELX restraints (see CIF file). The program Mercury $^{15}$ was used to generate the molecular and packing illustrations of all the complexes. Crystal data are summarized in Table 1.

Table 1 Crystallographic data

\begin{tabular}{|c|c|c|c|}
\hline Crystal & OxT & AdT & GlT \\
\hline \multirow{2}{*}{$\begin{array}{l}\text { Unit formula } \\
\text { Crystal size/mm }\end{array}$} & $\mathrm{C}_{9} \mathrm{H}_{15} \mathrm{~N}_{3} \mathrm{O}_{4}$ & $\mathrm{C}_{13} \mathrm{H}_{23} \mathrm{~N}_{3} \mathrm{O}_{4}$ & $\mathrm{C}_{9} \mathrm{H}_{17} \mathrm{~N}_{3} \mathrm{O}_{3} \mathrm{H}_{2} \mathrm{O}$ \\
\hline & $0.90 \times 0.30 \times 0.10$ & $0.40 \times 0.20 \times 0.15$ & $0.55 \times 0.30 \times 0.10$ \\
\hline Unit weight & 229.23 & 285.37 & 233.25 \\
\hline Crystal system & Orthorhombic & Monoclinic & Triclinic \\
\hline Space group & $P 2_{1} 2_{1} 2_{1}$ & $P 2_{1} / c$ & $P \overline{1}$ \\
\hline$a / \AA$ & 7.8795(16) & $7.014(3)$ & $7.1832(7)$ \\
\hline$b / \AA ̊ ̊$ & $9.760(2)$ & $12.065(5)$ & $8.9257(9)$ \\
\hline$c / \AA$ & $13.612(3)$ & $17.179(7)$ & $9.8008(10)$ \\
\hline$\alpha /^{\circ}$ & 90 & 90 & $71.298(1)$ \\
\hline$\beta /^{\circ}$ & 90 & $90.118(6)$ & $75.374(1)$ \\
\hline$\gamma /^{\circ}$ & 90 & 90 & 81.203(1) \\
\hline$V / \AA^{3}$ & $1046.8(4)$ & 1453(10) & 574.13(10) \\
\hline$Z$ & 4 & 4 & 2 \\
\hline Density $/ \mathrm{g} \mathrm{cm}^{-3}$ & 1.455 & 1.304 & 1.349 \\
\hline Absorption coefficient $/ \mathrm{mm}^{-1}$ & 0.12 & 0.10 & 0.11 \\
\hline$\theta$ range for data collection $/^{\circ}$ & $2.6-28.9$ & $2.1-28.5$ & $2.3-28.7$ \\
\hline \multicolumn{4}{|l|}{ Reflections } \\
\hline Collected & 9443 & 10766 & 5152 \\
\hline Independent & 1592 & 3687 & 2989 \\
\hline Observed & 1536 & 2527 & 2422 \\
\hline$R_{\text {int }}$ & 0.019 & 0.061 & 0.011 \\
\hline $\mathrm{w} R\left(F^{2}\right)$ & 0.0710 & 0.133 & 0.094 \\
\hline$R\left[F^{2}>2 \sigma\left(F^{2}\right)\right]$ & 0.0278 & 0.053 & 0.034 \\
\hline
\end{tabular}




\section{Results and discussion}

\section{Complex OxT}

The anhydrous orthorhombic crystals of OxT contain a hydrogen oxalate anion and a TBD cation in the asymmetric unit (Fig. 2a). The $\mathrm{O} 1$ and $\mathrm{O} 2$ atoms of the oxalate are H-bonded to TBD so as to form a symmetrical $\mathrm{R}_{2}^{2}(8)$ ring motif as shown in Fig. 1a. The carboxyl H-atom (H4O) of the hydrogen oxalate is donated to an anti lone pair of $\mathrm{O} 1$ (for details of $\mathrm{H}$-bond data see Table 2). This strong carboxylcarboxylate ( $\mathrm{COOH}^{\cdots}{ }^{-}$OOC) interaction leads to formation of an infinite $1 \mathrm{D}$ chain of hydrogen oxalate along the $a$-axis that is decorated by TBD cations (Fig. 2b). The resulting ribbons are densely stacked in a herringbone-like array as shown in Fig. 2c, where the polar hydrogen oxalate chain at the core appears to be encapsulated by the neighboring hydrophobic TBD moieties.

Unlike the three-dimensionally H-bonded structure of regular guanidinium-hydrogen oxalate hydrate ${ }^{4 a}$ (refcode GUHOXM, Cambridge Structure Database, ${ }^{16}$ CSD v5.34, Nov. 2012), the hydrogen oxalate in OxT is non-planar and exists in a twisted conformation [torsion angle O1-C8-C9-O3 = $\left.-54.13(15)^{\circ}\right]$ to facilitate formation of the $1 \mathrm{D}$ chain. Such an adapted orientation of hydrogen oxalate in OxT clearly deviates from the theoretical $90^{\circ}$ torsion angle of oxalate. ${ }^{17}$ Thus, the crystal structure of OxT demonstrates that by reducing the $\mathrm{H}$-bond complexity of the guanidinium ion, the molecular assembly can be directed towards a less complicated 1D supramolecular structure.

\section{Complex AdT}

The asymmetric unit of AdT (Fig. 3a) and the formation of onedimensional ribbons driven by carboxyl-carboxylate $\mathrm{H}$ bonding (Fig. 3b) are closely reminiscent of the observations made for OxT (Fig. 2a and 2b). However, there are two obvious differences between these two structures: first the carboxylate groups of adipic acid are not directly connected as for oxalic acid, but separated by the $-\left(\mathrm{CH}_{2}\right)_{4}$ - linker, and second the 1D ribbons of AdT are planar and aligned two-dimensionally in the crystallographic $b c$-plane to form an interlocked sheet-like topology (Fig. 3b), whereas OxT shows a non-planar herring-
Table 2 Selected hydrogen-bond distances $(\AA)$ and angles $\left({ }^{\circ}\right)^{a}$

\begin{tabular}{|c|c|c|c|c|}
\hline $\mathrm{D}-\mathrm{H} \cdots \mathrm{A}$ & $\mathrm{D}-\mathrm{H}$ & $\mathrm{H} \cdots \mathrm{A}$ & $\mathrm{D} \cdots \mathrm{A}$ & $\angle(\mathrm{D}-\mathrm{H} \cdots \mathrm{A})$ \\
\hline \multicolumn{5}{|l|}{ Crystal OxT } \\
\hline $\mathrm{N} 1-\mathrm{H} 1 \cdots \mathrm{O} 1$ & 0.86 & 1.98 & $2.839(14)$ & 179 \\
\hline $\mathrm{N} 3-\mathrm{H} 3 \cdots \mathrm{O} 2$ & 0.86 & 1.94 & $2.817(13)$ & 174 \\
\hline $\mathrm{O} 4-\mathrm{H} 4 \mathrm{O} \cdots \mathrm{O} 1^{\mathrm{i}}$ & $0.90(2)$ & $1.65(2)$ & $2.549(13)$ & $172(18)$ \\
\hline \multicolumn{5}{|l|}{ Crystal AdT } \\
\hline $\mathrm{N} 1-\mathrm{H} 1 \cdots \mathrm{O} 1^{\mathrm{ii}}$ & 0.88 & 1.92 & $2.796(2)$ & 179 \\
\hline $\mathrm{N} 3-\mathrm{H} 3 \cdots \mathrm{O} 2^{\mathrm{ii}}$ & 0.88 & 1.85 & $2.723(2)$ & 173 \\
\hline $\mathrm{O} 4-\mathrm{H} 4 \cdots \mathrm{O} 2^{\mathrm{iii}}$ & $0.99(3)$ & $1.56(3)$ & $2.536(2)$ & $170(3)$ \\
\hline \multicolumn{5}{|l|}{ Crystal GIT } \\
\hline $\mathrm{N} 1-\mathrm{H} 1 \cdots \mathrm{O} 1$ & 0.88 & 1.98 & $2.855(11)$ & 176 \\
\hline $\mathrm{N} 3-\mathrm{H} 3 \cdots \mathrm{O} 2$ & 0.88 & 1.89 & $2.772(11)$ & 176 \\
\hline $\mathrm{O} 3-\mathrm{H} 3 \mathrm{O} \cdots \mathrm{O} 1^{\mathrm{iv}}$ & $0.85(17)$ & $1.96(17)$ & $2.741(11)$ & $152(14)$ \\
\hline O1W-H11W $\cdots \mathrm{O} 2$ & $0.87(2)$ & $1.93(2)$ & $2.802(12)$ & $176(19)$ \\
\hline $\mathrm{O} 1 \mathrm{~W}-\mathrm{H} 12 \mathrm{~W} \cdots \mathrm{O} 3^{\mathrm{v}}$ & $0.83(2)$ & $2.06(2)$ & $2.887(14)$ & $174(2)$ \\
\hline
\end{tabular}

${ }^{a}$ Symmetry codes i) $x-1 / 2,1 / 2-y, 1-z$; ii) $-x+1,-y+1,-z+$ 1 ; iii) $x,-y+3 / 2, z+1 / 2$; iv) $-x, 1-y, 2-z$; v) $-x,-y, 2-z$.

bone-like pattern. The sheets in AdT are stacked within the $\pi \cdots \pi$ interplanar distance range $\sim 3.1-3.7 \AA[$ for $(\mathrm{N} 1-\mathrm{N} 2-$ N3) $\mathbf{T B D}^{\cdots} \mathbf{T B D}^{\prime}{ }_{(\mathrm{N} 1-\mathrm{N} 2-\mathrm{N} 3)}$ and $\left.\left(\mathrm{COO}^{-}{ }^{-\cdots} \mathrm{COO}^{-}\right)\right]$and within the van der Waals space of 2.287-2.394 $\AA$ for adipate/TBD $\mathrm{C}_{(\mathrm{sp} 3)^{-}}$ $\mathrm{H} \cdot \mathrm{H}-\mathrm{C}_{(\mathrm{sp} 3) \text {-adipate }}$ (Fig. S1, ESI $\dagger$ ).

The crystallization experiment between the adipic acid and TBD was set up to obtain a $2: 1$ crystalline complex containing two TBD cations and a dianion of adipic acid. In fact, the resulting AdT crystal contains a monoanion rather than a dianion. To facilitate a second deprotonation step by breaking the strong carboxyl-carboxylate interaction, three additional crystallization experiments with increased TBD concentrations (adipic acid : TBD ratios $1: 3,1: 4$ and $1: 5$ ) and one controlled experiment with $1: 1$ ratio were carried out. The $1: 1$ mixture instantaneously afforded the familiar AdT type of crystal, whilst other mixtures did not yield crystals. This apparently confirms that the $1: 1$ ratio of adipic acid and TBD is the thermodynamically favorable composition for crystal formation. a)

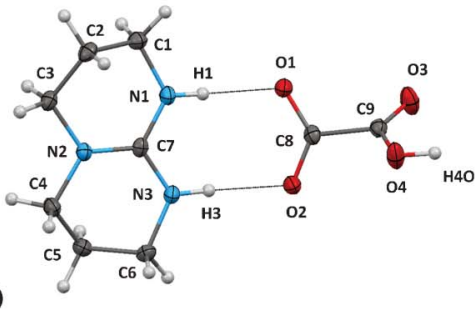

b)

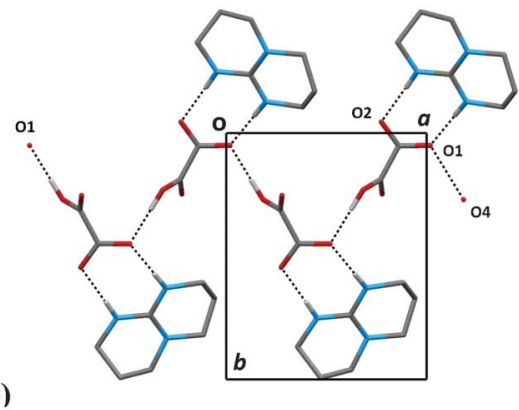

c)

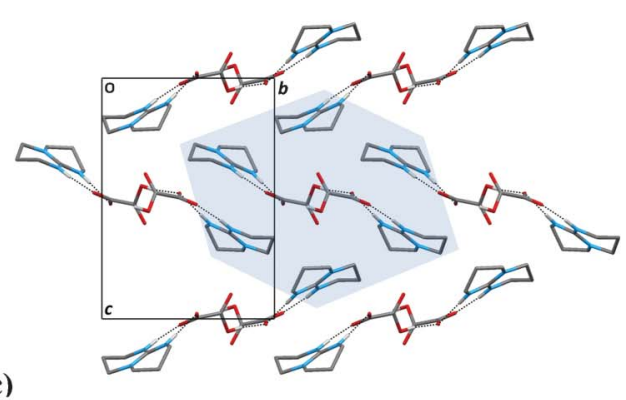

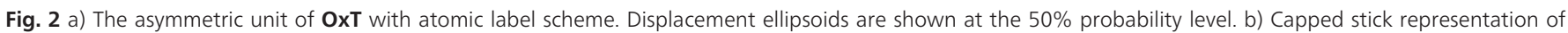

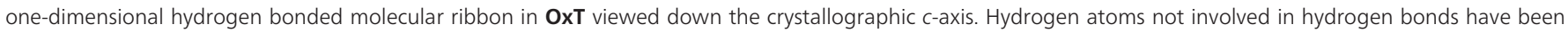

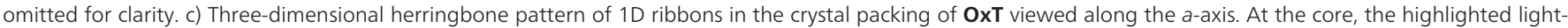
blue shade represents the encapsulation of polar hydrogen-oxalate chain by hydrophobic TBD molecules. 


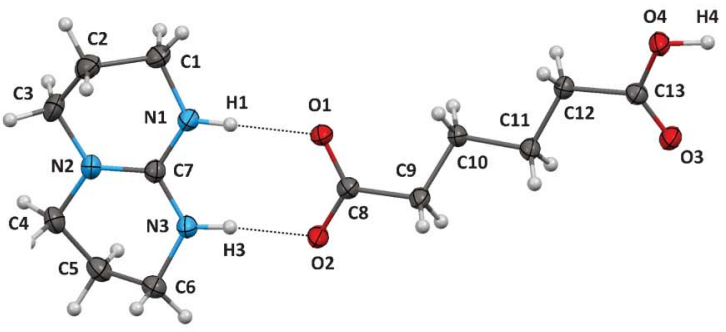

b)

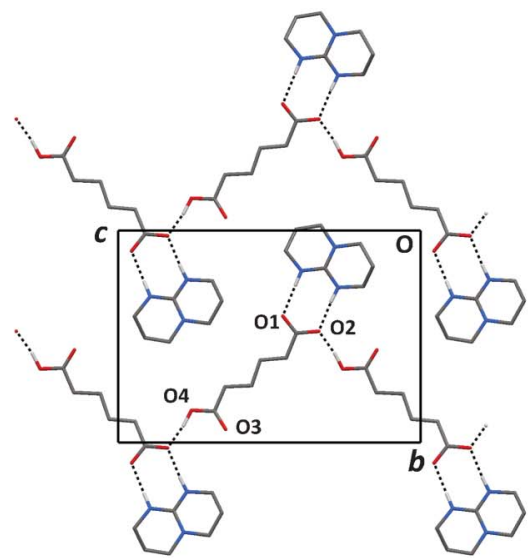

Fig. 3 a) The asymmetric unit of crystal AdT with atom label scheme. Displacement ellipsoids are shown at the 50\% probability level. b) The 1D infinite chains in AdT running along the crystallographic $c$-axis. These chains are interlocked in a zigzag pattern which forms a layer parallel to plane-bc. The non-hydrogen bonded hydrogen atoms have been omitted for clarity.

In theory, a dicarboxylic acid should form a dianion upon proton exchange with a base, though in reality the structural characteristics of the acid and base involved may also promote formation of monoanions. This is clear from a survey of dicarboxylic acids in the CSD, where mono- and dianions of oxalic acid are equally common ( 190 structures each). The distribution between mono- and dianion for succinic acid with a $-\left(\mathrm{CH}_{2}\right)_{2}-$ linker $\left(\mathrm{Succ}^{-}=48\right.$; $\left.\mathrm{Succ}^{2-}=65\right)$ and adipic acid $\left(\mathrm{Adp}^{-}=13 ; \operatorname{Adp}^{2-}=34\right)$, reveals a trend: when the aliphatic link between the two carboxylic groups is extended, the ratio of mono/dianion decreases.

\section{Complex GIT}

The asymmetric unit of the GlT complex is composed of the glycolate anion, TBD and a water molecule (Fig. 4a). The TBD and glycolate ions are $\mathrm{H}$ bonded by two ${ }^{+} \mathrm{N}-\mathrm{H}^{\cdots} \mathrm{O}^{-}$interactions forming a $\mathrm{R}_{2}^{2}(8)$ motif. An TBD-glycolate complex is interacting with another TBD-glycolate through glycolate $\mathrm{O}-\mathrm{H} \cdots \mathrm{O}_{\text {carboxylate }}$ interactions and generating a tetramer through the new $\mathrm{R}_{2}^{2}(10)$ ring motif, (Fig. 4b). Co-crystallized water molecules serve as links between tetramers through formation of a third hydrogen bonded ring motif, $\mathrm{R}_{4}^{4}(14)$, thus producing a supramolecular ribbon along the $b$-axis (Fig. $4 \mathrm{~b}$ ). The compact and staggered spatial arrangement of ribbons in AdT is significantly influenced by the weak interactions such as $\mathrm{N}_{1} \cdots \mathrm{H}_{62}-\mathrm{C}_{6}(2.67 \AA$ ) and $\mathrm{C}-\mathrm{H} \cdots \mathrm{O}$ (see Table 3 ).

There is no crystal structure involving native guanidine and glycolic acid in the CSD, but a close structural analogue, the guanidinium-bicarbonate, is reported (refcode: DUMPUW). ${ }^{18}$ This bicarbonate is a methylene group shorter than the glycolate, but it forms a very similar $\mathrm{H}$-bonded tetramer. As the bicarbonate salt is devoid of water molecules, the tetramers are, however, not linked into chains but generate a compact 3D network (see ESI, $\uparrow$ Fig. S2).

\section{C-H $\cdots \mathrm{O}$ interactions and crystal packing}

Although the $\mathrm{C}-\mathrm{H} \cdots \mathrm{O}$ hydrogen bond is a weak non-covalent interaction, in molecular self-assembly its role is proficient enough to direct the $3 \mathrm{D}$ aggregations. This interaction is formed between $\mathrm{C}$ and $\mathrm{O}$ atoms within a distance range of 3.0$4.0 \AA^{19}{ }^{19}$ In the present study the $\mathrm{N}-\mathrm{H} \cdots \mathrm{O}$ and $\mathrm{O}-\mathrm{H} \cdots \mathrm{O}$ hydrogen bonds are electrostatic and directive in binary crystalline complex formation. The role of the aliphatic skeleton of TBD and its contribution to the crystal packing is more variable due to the conformational flexibility of the fused ring system and the multiple and nondirective weak $\mathrm{C}-\mathrm{H}$ a)

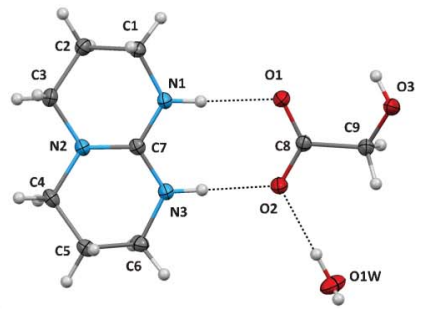

b)

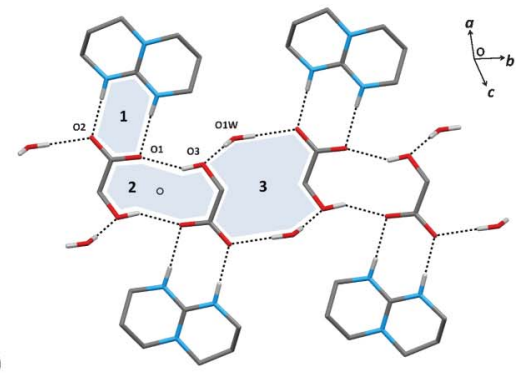

c)

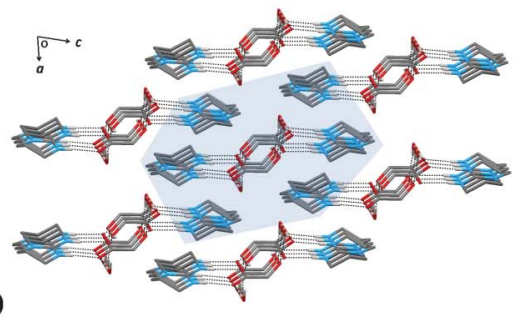

Fig. 4 a) The asymmetric unit of GIT. Displacement ellipsoids are shown at the $50 \%$ probability level. b) One-dimensional infinite molecular ribbon in GIT. Three

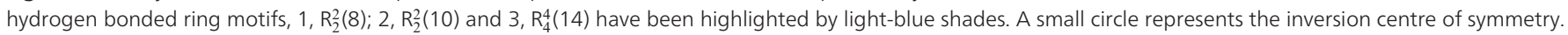
c) The crystal packing of one-dimensional ribbons viewed along the $b$-axis. Light-blue shade represents the hydrophobic surroundings of adipate:water chain. Hydrogen atoms except $\mathrm{H}$ bonded have been omitted for clarity in b) and c). 
Table $3 \mathrm{C}-\mathrm{H} \cdots \mathrm{O}$ interactions with distances ( $(\AA)$ and angles $\left({ }^{\circ}\right)$

\begin{tabular}{|c|c|c|c|c|}
\hline Complex & $\mathrm{C}-\mathrm{H} \cdots \mathrm{O}$ & $\mathrm{C}-\mathrm{H} \cdots \mathrm{O}$ & $\mathrm{C} \cdots \mathrm{O}$ & $\angle(\mathrm{C}-\mathrm{H} \cdots \mathrm{O})$ \\
\hline \multirow[t]{2}{*}{ OxT } & 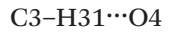 & 2.54 & $3.258(2)$ & 128.5 \\
\hline & 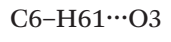 & 2.61 & $3.590(2)$ & 167.0 \\
\hline \multirow[t]{2}{*}{ AdT } & $\mathrm{C} 2-\mathrm{H} 22 \cdots \mathrm{O} 3$ & 2.54 & $3.485(4)$ & 158.9 \\
\hline & $\mathrm{C} 6-\mathrm{H} 62 \cdots \mathrm{O} 4$ & 2.59 & $3.394(4)$ & 137.8 \\
\hline GIT & C5-H51O1 & 2.45 & $3.237(2)$ & 135.3 \\
\hline
\end{tabular}

donor implications. In the OxT, AdT and GIT structures there is a variety of $\mathrm{C}-\mathrm{H} \cdots \mathrm{O}$ interactions between the TBD methylene $\mathrm{H}$ atoms and strong $\mathrm{H}$-bond accepting $\mathrm{O}$ atoms in either the carboxyl groups (see Fig. 5a and 5b) or water (Fig. 5c), which are greatly involved in creating a densely packed crystalline network. The carboxyl group in OxT coordinates with two TBD from different layers and forms $\mathrm{H}-\mathrm{O} \cdots \mathrm{H}-\mathrm{C}_{3}$ and $>\mathrm{C}=\mathrm{O} \cdots \mathrm{H}-\mathrm{C}_{6}$ contacts, (bond lengths and angles are summarized in Table 3), where both the TBD orient perpendicularly to the carboxyl plane to avoid steric conflict (Fig. 5a). By contrast, in AdT the carboxyl group of the planar and layered hydrogen adipate is aligned parallel to the plane of $\mathbf{T B D}$, interacting with $\mathrm{H}-\mathrm{C}_{2}$ and $\mathrm{H}-\mathrm{C}_{6}$ (Fig. 5b). Exceptionally the $\mathrm{C}-\mathrm{H} \cdots \mathrm{O}$ interaction in GlT involves an additional solvated water molecule as acceptor rather than a carboxylate which is fully engaged in strong $\mathrm{H}$ bonding with the TBD and water (Fig. 5c).

\section{Conclusion}

Here we have pursued a crystalline complex formation approach based on the $\mathrm{R}_{2}^{2}(8)$ synthon formed by dicarboxylic

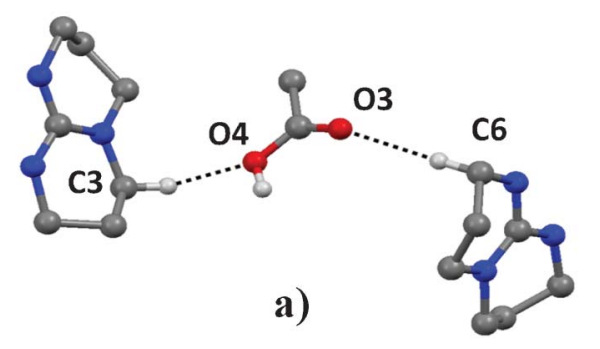

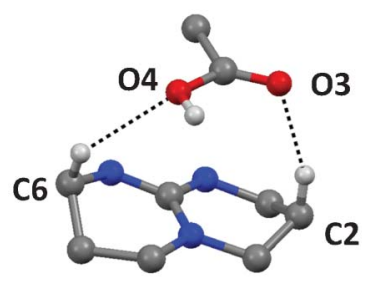

b)

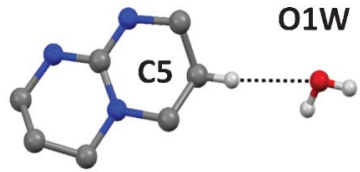

c)
Fig. $5 \mathrm{C}-\mathrm{H} \cdots \mathrm{O}$ interactions formed by TBD with a) carboxyl in $\mathbf{O x T}$, b) and AdT, and c) with water in GIT acids and a TBD base. This strategy implies controlling the capacity of a potential multiple $\mathrm{H}$-atom donor such as native guanidinium cation. This restrictive path can generate ordered and relatively less complicated lower order crystalline molecular networks (e.g. OxT and GIT). Complexes building an infinite $\mathrm{H}$-bonded network of $1 \mathrm{D}$-chains or tapes, are of interest for materials such as gelators. ${ }^{20}$ Hence this method may provide a model for further materials preparation. TBD and its weak aliphatic $\mathrm{C}-\mathrm{H}$ co-ordination should offer insight into the structurally and biologically relevant interactions of similar groups of molecules.

\section{Notes and references}

1 (a) G. R. Desiraju, Crystal Engineering: The Design of Organic Solids, Elsevier, Amsterdam, 1989; (b) G. R. Desiraju, Angew. Chem., Int. Ed. Engl., 1995, 34, 2311-2327; (c) C. B. Aakeroy and K. R. Seddon, Chem. Soc. Rev., 1993, 22, 397-407.

2 (a) G. R. Desiraju, Acc. Chem. Res., 2002, 35, 565-573; (b) O. Félix, M. W. Hosseini, A. De Cian and J. Fischer, Angew. Chem., Int. Ed. Engl., 1997, 36, 102-104; (c) A. Mukherjee and G. R. Desiraju, Chem. Commun., 2011, 47, 4090-4092; (d) M. Du, Z.-H. Zhang and X.-J. Zhao, Cryst. Growth Des., 2005, 5, 1199-1208; (e) H. P. Jones, R. J. Davey and B. G. Cox, J. Phys. Chem. B, 2005, 109, 5273-5278; $(f)$ J. F. Remenar, S. L. Morissette, M. L. Peterson, B. Moulton, J. M. MacPhee, H. R. Guzmán and Ö. Almarsson, J. Am. Chem. Soc., 2003, 125, 8456-8457; (g) S.-p. Chen, L.-l. Pan, Y.x. Yuan, X.-x. Shi and L.-j. Yuan, Cryst. Growth Des., 2009, 9, 2668-2673; (h) D. R. Trivedi and P. Dastidar, Cryst. Growth Des., 2006, 6, 1022-1026; (i) K. Kinbara, Y. Hashimoto, M. Sukegawa, H. Nohira and K. Saigo, J. Am. Chem. Soc., 1996, 118, 3441-3449; (j) J. C. MacDonald, P. C. Dorrestein and M. M. Pilley, Cryst. Growth Des., 2001, 1, 29-38.

3 (a) M. C. Etter, Acc. Chem. Res., 1990, 23, 120-126; (b) E. D. Raczyńska, M. K. Cyrański, M. Gutowski, J. Rak, J.-F. Gal, P.-C. Maria, M. Darowska and K. Duczmal, J. Phys. Org. Chem., 2003, 16, 91-106; (c) J. Han, C.-W. Yau, C.-K. Lam and T. C. W. Mak, J. Am. Chem. Soc., 2008, 130, 10315-10326; (d) W.-Z. Xu, J. Sun, Z.-T. Huang and Q.Y. Zheng, Chem. Commun., 2009, 171-173; (e) A. C. Soegiarto, A. Comotti and M. D. Ward, J. Am. Chem. Soc., 2010, 132, 14603-14616; ( $f$ ) K. Latham, J. E. Downs, C. J. Rix and J. M. White, J. Mol. Struct., 2011, 987, 74-85.

4 (a) J. Adams, Acta Crystallogr., Sect. B: Struct. Crystallogr. Cryst. Chem., 1978, 34, 1218-1220; (b) V. VidenovaAdrabinska, E. Obara and T. Lis, New J. Chem., 2007, 31, 287-295; (c) G. Smith, U. D. Wermuth, D. J. Young and P. C. Healy, Acta Crystallogr., Sect. E: Struct. Rep. Online, 2007, 63, o556-0557; (d) G. Smith and U. D. Wermuth, Acta Crystallogr., Sect. C: Cryst. Struct. Commun., 2010, 66, o575-0580.

5 (a) S. H. Oakley, D. B. Soria, M. P. Coles and P. B. Hitchcock, Dalton Trans., 2004, 537-546; (b) U. Wild, P. Roquette, E. Kaifer, J. Mautz, O. Hübner, H. Wadepohl and H.-J. Himmel, Eur. J. Inorg. Chem., 2008, 2008, 1248-1257; (c) M. P. Coles, Chem. Commun., 2009, 3659-3676. 
6 (a) D. Simoni, M. Rossi, R. Rondanin, A. Mazzali, R. Baruchello, C. Malagutti, M. Roberti and F. P. Invidiata, Org. Lett., 2000, 2, 3765-3768; (b) D. J. Phillips and A. E. Graham, Synlett, 2010, 769, 773; (c) R. C. Pratt, B. G. G. Lohmeijer, D. A. Long, R. M. Waymouth and J. L. Hedrick, J. Am. Chem. Soc., 2006, 128, 4556-4557.

7 C. D. N. Gomes, O. Jacquet, C. Villiers, P. Thuéry, M. Ephritikhine and T. Cantat, Angew. Chem., Int. Ed., 2012, 51, 187-190.

8 (a) I. Binkowska, A. Jarczewski, A. Katrusiak, G. Wojciechowski and B. Brzezinski, J. Mol. Struct., 2001, 597, 101-107; (b) A. Huczyński, M. Ratajczak-Sitarz, A. Katrusiak and B. Brzezinski, J. Mol. Struct., 2008, 888, 84-91.

9 V. N. Yadav and C. H. Görbitz, CrystEngComm, 2013, 15, 439-442.

10 V. N. Yadav and C. H. Görbitz, Cryst. Growth Des., 2013, 13, 2174-2180.

11 T. C. W. Mak and F. Xue, J. Am. Chem. Soc., 2000, 122, 9860-9861.

$12 \mathrm{p} K_{\mathrm{a}}$, Calculated using Advanced Chemistry Development (ACD/Labs) Software V11.02 ( ${ }^{\circledR} 1994-2013$ ACD/Labs).

13 H. C. Brown, D. H. McDaniel and O. Häfdinger, Determination of Organic Structures by Physical Methods, ed. E. A. Braude and F. C. Nachod, Academic Press, New York, 1955.

14 (a) Bruker APEX2, SAINT-Plus and SADABS, Bruker AXS Inc., Madison, Wisconsin, USA, 2007; (b) G. Sheldrick, Acta Crystallogr., Sect. A: Found. Crystallogr., 2007, 64, 112-122.

15 C. F. Macrae, I. J. Bruno, J. A. Chisholm, P. R. Edgington, P. McCabe, E. Pidcock, L. Rodriguez-Monge, R. Taylor, J. van de Streek and P. A. Wood, J. Appl. Crystallogr., 2008, 41, 466-470.

16 F. Allen, Acta Crystallogr., Sect. B: Struct. Sci., 2002, 58, 380-388.

17 D. Y. Naumov, E. V. Boldyreva, N. V. Podberezskaya and J. A. K. Howard, Solid State Ionics, 1997, 101-103, 1315-1320.

18 D. A. Baldwin, L. Denner, T. J. Egan and A. J. Markwell, Acta Crystallogr., Sect. C: Cryst. Struct. Commun., 1986, 42, 1197-1199.

19 (a) G. R. Desiraju and T. Steiner, The Weak Hydrogen Bond In Structural Chemistry and Biology, Oxford University Press, Oxford, 1999; (b) G. R. Desiraju, Acc. Chem. Res., 1996, 29, 441-449; (c) T. Steiner, Crystallogr. Rev., 2003, 9, 177-228.

20 R. Luboradzki, O. Gronwald, M. Ikeda, S. Shinkai and D. N. Reinhoudt, Tetrahedron, 2000, 56, 9595-9599. 